Article

\title{
Analysis of North American Newspaper Coverage of Bionics Using the Disability Studies Framework
}

\author{
Sonum Panesar and Gregor Wolbring * \\ Department of Community Health Sciences, Specialization in Community Rehabilitation and \\ Disability Studies, University of Calgary, Calgary, AL T2N4N1, Canada; \\ E-Mail: sonum.panesar@gmail.com
}

* Author to whom correspondence should be addressed; E-Mail: gwolbrin@ ucalgary.ca;

Tel.: +1-403-210-7083; Fax: +1-403-220-6494.

Received: 6 December 2013; in revised form: 14 January 2014 / Accepted: 22 January 2014 /

Published: 6 February 2014

\begin{abstract}
Bionics are a set of technology products that are constantly evolving. Bionics are proposed as body add-ons or replacement for many body parts (ears, eyes, knees,-neural prostheses, joints, muscles, kidney, liver, cartilage lungs, discs, pancreas, dental pulp, skin, hippocampus, legs and hands), and functions such as speech. Two main applications of bionic products are discussed; one being for the restoration of body abilities to a species-typical norm and the other being the addition of abilities to the body that are not species-typical. Disabled people are one main group perceived to be in need of therapeutic interventions that use various bionic products. So far, therapeutic interventions are about restoration to the species-typical norm. However, therapeutic bionic products increasingly give the wearer beyond normal body abilities (therapeutic enhancements). Many so-called non-disabled people want the same enhanced body-abilities especially through non-invasive bionic products (e.g., non-invasive brain machine interfaces, exoskeletons). The media has the ability to shape public perceptions with numerous consequences. The purpose of this study was to provide quantitative and qualitative data on how bionic technologies and its users are portrayed in North American newspapers. Data was obtained from 1977 to 2013 from the Canadian Newsstand complete database which covers over 300 English language Canadian newspapers and two Canadian newspapers, one with national focus (The Globe and Mail) and one with local focus (Calgary Herald), and from 1980-2013 from one American newspaper with national reach (The New York Times). The study found (a) an almost always positive portrayal of bionics; (b) coverage of bionics mostly within a medical framework; (c) a predominantly stereotypical and negative
\end{abstract}


portrayal of individuals with disabilities; and (d) a hierarchy of worthiness between different assistive devices such as a reporting bias favoring artificial legs over wheelchairs. At the same time the study did not find any engagement with social and ethical issues that are already raised about bionics in the literature, such as the increasing desire for enhancements, the use of bionics for non-therapeutic purposes and the issues socially disadvantaged people might face in the wake of bionic advancements. We posit that the newspapers generate a bionic discourse culture that is problematic for disabled people and other socially disadvantaged groups and that they do not prepare readers for the challenges that bionic advancements will pose for the general population in the future.

Keywords: bionics; brain machine interface; newspapers; disabled people; therapeutics; people with disabilities; therapeutic enhancement

\section{Introduction}

The field of bionics is based on the union of living organisms and machines [1]. Bionics are proposed as replacements for many body parts (ears, eyes, knees, neural prostheses, joints, muscles, kidney, liver, cartilage, lungs, discs, pancreas, dental pulp, skin, hippocampus, legs and hands), and for functions such as speech [1-23]. Two main visions of bionic product use are discussed within and outside academia; one being to regain species-typical abilities and one to generate abilities beyond the species-typical.

\subsection{Bionics and Disabled People}

Disabled people are one main group seen to be in therapeutic need of various bionic products [24]. This group of disabled people includes injured soldiers and veterans [25]. The Defense Advanced Research Projects Agency (DARPA) USA has numerous active research projects related to bionics and prosthetics [25-31]. So far, treatment and rehabilitation need has been linked to a loss of abilities expected from a normal or species-typical body. However, increasingly bionic products used for therapeutic reasons can give recipients beyond species-typical abilities (therapeutic enhancement [24]). Artificial legs, one therapeutic device, have received a lot of attention recently in part due to the controversy surrounding the Paralympian and Olympian, Oscar Pistorius. He wanted to compete in the Olympics but was initially declined that option as his artificial legs were labeled as a techno doping device because they were classified as giving him an unfair advantage [32,33]. Although he is not outperforming the best Olympic athletes yet, it is expected that some bionic runner eventually will do so [34].

Bionic/artificial legs pose challenges within and outside the sports world, and for disabled people and non-disabled people alike. As for disabled people it influences for example the imagery/-portrayal of wheelchairs [35] and low tech prosthetics and for non-disabled people the challenge is how to react to a situation where the bionic leg person outperforms the species-typical leg person. We posit that many therapeutic bionic/artificial body part replacement or add-on that enable body abilities beyond 
the species-typical will pose ability expectation challenges for people with species-typical body abilities and people perceived as having sub species-typical body abilities (disabled people).

\subsection{Bionics and Non-Disabled People}

Bionic/artificial body part replacements or add-ons are also used for non-therapeutic purposes and by non-disabled people. DARPA for example is not only focusing on injured soldiers and veterans but also on healthy, active duty soldiers [25] and non-invasive brain machine interfaces that add new abilities to the body are developed for therapeutic purposes and non-therapeutic purposes such as gaming [36]. Indeed bionic/artificial body part replacements and add-ons and other products that add new abilities to the body are desired by species-typical individuals [37]. Ability enhancements of the species-typical body in general [25,38-52] and enabled by bionics [53-60] are discussed extensively in the literature (sport and doping in sport related literature not listed).

\subsection{Switching Sides}

The Nuffield Council of Bioethics (UK) just proposed classifying non-invasive brain machine interfaces and other emerging neuro-technologies as medical devices [61] which raises the question of which of the ability enhancing bionic/artificial body part replacements and add-on products will eventually be dealt with under the label of medical technologies/devices and which won't.

Bostrom proposed to make cognitive enhancements available through public health care [62] which raises the question of which bionic products discussed outside of the medical realm will become part of the producer and/or consumer driven medicalization dynamic [63-70].

Our study used a disability studies lens which "refers generally to the examination of disability as a social, cultural, and political phenomenon in contrast to clinical, medical, or therapeutic perspectives on disability" [71] to investigate the content of the newspapers covered. We present in Section 3 qualitative and quantitative results addressing the following research questions: (a) which social groups (Section 3.1); (b) which bionic products (Section 3.2) are mentioned; (c) how are bionics, disabled people and their non-bionic assistive devices such as wheelchairs portrayed (Section 3.3); (d) what issues are mentioned in relation to bionics (Section 3.4) including whether enhancement is a topic mentioned (Section 3.5). In Section 4 implications of the results are discussed and in Section 5 we provide some thoughts as to future steps that should be taken to ensure that society is well equipped to deal with the progress in bionics.

\section{Methods}

\subsection{Analytical Framework}

We used a disability studies lens [71-73] and a framing analysis [74] as our analytical frameworks to investigate the newspaper articles. Structural [75], content [76] and issue-specific framing [77,78] are three ways of framing. According to Entman, "[to] frame is to select some aspects of a perceived reality and make them more salient in a communicating text, in such a way as to promote a particular problem definition, causal interpretation, moral evaluation, and/or treatment recommendation for the item described. Typically frames diagnose, evaluate, and prescribe, then, define problems-determine 
what a causal agent is doing with what costs and benefits, usually measured in terms of common cultural values; diagnose causes-identify the forces creating the problem; make moral judgments-evaluate causal agents and their effects; and suggest remedies-offer and justify treatments for the problems and predict their likely effects" [79].

Disability Studies perceives disability as a social, cultural, and political phenomenon as opposed to a clinical, medical, or therapeutic phenomenon [71-73]. As such it is of interest to the disability studies field how disability is framed within given sources such as newspaper articles. From a disability studies perspective it is also highly relevant how a topic is framed, what reality is made salient, what is described as a problem, its cause and solution and which and whose cultural values are evident.

According to Entman frames have at least four locations in the communication process: the communicator, the text, the receiver, and the culture [79] (see also [80]). Our content analysis focuses on how the communicator (the newspaper) frames the topic of bionics. According to Collins et al. persuasion is one media effect and encompasses the message, who is used as a source and the "persuadability of media consumers" [81]. We use the disability studies lens to assess the effect and the consequences of the framing of bionics for disabled and non-disabled people. Concrete our study answered the following research questions: (a) which social groups (Section 3.1); (b) which bionic products are mentioned (Section 3.2); (c) how are bionics, disabled people and their non-bionic assistive devices such as wheelchairs portrayed (Section 3.3); (d) what issues are mentioned in relation to bionics (Section 3.4) including whether enhancement is a topic mentioned (Section 3.5).

\subsection{Data Source}

We accessed 300 Canadian newspapers published between 1977-2013 through the ProQuest database, "Canadian newsstand complete", which we accessed through the University of Calgary library (21 September 2013). We furthermore accessed the articles of two Canadian newspapers, one with national focus (The Globe and Mail) and one with local focus (Calgary Herald) published between 1977-2013, through databases accessible through the University of Calgary library (2 May 2013 and 21 September 2013). Finally, we accessed articles of The New York Times, an influential American newspaper [33] from 1980-2013 through the University of Calgary library (21 September 2013). All databases were searched for the term "bionics" in the full text. The articles identified as containing the term "bionics" were further searched for keywords linked to the disability studies framework and the research questions of this study to generate quantitative data. The $n=270$ Calgary Herald articles and the $n=392$ The Globe and Mail articles found with the term "bionics" (2 May 2013) were downloaded as PDF documents and uploaded into ATLAS.ti ${ }^{\odot}$, a qualitative data analysis software [82], for further qualitative examination. Certain articles from the Canadian newsstand complete database and The New York Times were downloaded as PDF from their ProQuest database and analyzed by reading the PDF.

\subsection{Data Analysis}

Two different groups or families were created in the ATLAS.ti ${ }^{\odot}$ hermeneutic unit via the Family Manager function; one for the Calgary Herald and one for The Globe and Mail articles. Within the families, the articles were organized by year of publication. The Auto Coding function in ATLAS.ti ${ }^{\odot}$, 
was used to perform deductive coding of the material using terms fitting the disability studies framework and the research questions to search all articles for a given term (e.g., different social groups, the visibility of terms linked to impairment or disability, terms linked to social issues known to be of relevance to disabled people). We also performed inductive coding by reading through all of the articles and marking themes fitting the disability studies framework and the research questions as they were identified. Qualitative and quantitative data was generated from the coded data.

\subsection{Limitations}

We only looked for English language content. This means our study was not tailored to look at one province in Canada (Quebec) where the first language is French. Furthermore, we only looked at one US newspaper. Given the sources we investigated, our results cannot be used to generalize our findings whether for the whole of Canada, North-America or beyond. Furthermore, nowadays comments from readers are often posted on the webpages of newspapers. These comments are not present in the articles downloaded from the ProQuest database. This means our study was not equipped to look at the public sentiment toward various articles based on webpage comments. This might be a future research angle, along with looking at Canadian French language media content and other newspapers and other media sources. Finally, we only investigated the coverage of "bionics". Articles that cover bionic products without using the term "bionics" in the text were not captured; for example in the Canadian newsstand complete $n=1,029$ article have "Pistorius" in the text whereby of these only $n=30$ have also bionic in the text. To give another example the terms "brain-machine"/"brain computer" were present in $n=81 / 140$ articles of the Canadian newsstand complete but only in 3/6 articles of the Canadian newsstand complete containing the term "bionics".

\section{Results}

\subsection{Who is Mentioned?}

Who is mentioned as a source and/or stakeholder is seen as one way to persuade the reader [81]. At the same time who is mentioned leads to different narratives and the salience of different realities linked to different social groups including the promotion of a particular problem definition, causal interpretation, moral evaluation, and/or treatment recommendation for the item described. As such, one main focus of disability studies is to investigate who is mentioned in a given discourse, whether it involves disabled people and if yes how it involves disabled people.

Data from Table 1 indicates that the phrase "people with disabilities" and "disabled people", which are often used to cover the social situation of disabled people are not used very often, if at all. However, terms that indicate a medical focus of disabled people are highly visible (amputee, patient, various terms containing impair*).

Disabled people are one invisible socially disadvantaged group however Table 1 furthermore reveals that other groups one could also classify as socially disadvantaged such as immigrants, "the poor" or Indigenous People are not visible either. On the other hand, the industrial complex (corporation, industry, business) and government are highly visible. Another visible group is the military complex (soldiers, veteran and military). 
Table 1. Mentioning of groups in the newspaper coverage of bionics.

\begin{tabular}{|c|c|c|c|c|}
\hline Codes & $\begin{array}{c}\text { Canadian Newsstand } \\
\text { Complete } n=4,826\end{array}$ & $\begin{array}{c}\text { Calgary } \\
\text { Herald } n=\mathbf{2 7 0}\end{array}$ & $\begin{array}{c}\text { The Globe and } \\
\text { Mail } n=392\end{array}$ & $\begin{array}{l}\text { The New York } \\
\text { Times } n=492\end{array}$ \\
\hline \multicolumn{5}{|l|}{ Aboriginal } \\
\hline People/Indigenous & $7 / 3 / 0$ & $2 / 0 / 0$ & $2 / 0 / 0$ & $0 / 3 / 0$ \\
\hline \multicolumn{5}{|l|}{ People/First nations } \\
\hline Amputee & 118 & 12 & 12 & 13 \\
\hline Business & 1,296 & 49 & 89 & 138 \\
\hline Caregiver & 4 & 0 & 0 & 9 \\
\hline Corporate & 129 & 5 & 21 & 129 \\
\hline Cyborg & 55 & 5 & 2 & 10 \\
\hline Family/ies & $1,062 / 175$ & 61 & 89 & 1,130 \\
\hline Government & 425 & 32 & 50 & 38 \\
\hline Immigrants & 22 & 2 & 5 & 6 \\
\hline Impair* & 71 & 3 & 0 & 71 \\
\hline Industry & 534 & 34 & 56 & 87 \\
\hline Inuit & 17 & 0 & 0 & 0 \\
\hline Military & 255 & 12 & 19 & 27 \\
\hline Nurses & 33 & 3 & 8 & 3 \\
\hline Parents & 125 & 28 & 36 & 71 \\
\hline Patient & 323 & 27 & 33 & 60 \\
\hline \multicolumn{5}{|l|}{ People with } \\
\hline $\begin{array}{l}\text { Disabilities/disabled } \\
\text { people }\end{array}$ & $8 / 27$ & $0 / 1$ & $0 / 0$ & $1 / 5$ \\
\hline Physicians & 46 & 4 & 8 & 19 \\
\hline Society & 391 & 31 & 27 & 56 \\
\hline Soldier & 171 & 10 & 12 & 24 \\
\hline The poor & 38 & 3 & 4 & 12 \\
\hline Therapist & 75 & 4 & 7 & 9 \\
\hline Veteran & 348 & 23 & 32 & 35 \\
\hline Women & 888 & 115 & 195 & 221 \\
\hline
\end{tabular}

Table 1 gives only pure hit-counts but does not tell one what was covered and even whether all hits are relevant. Therefore, as to social groups we looked further into article that covered military, soldiers and veterans. Most articles that contained the terms military and bionics in the Calgary Herald, The Globe and Mail and The New York Times were false positive articles meaning they did not cover bionic products; for example some just covered television shows, or there were phrases such as "bionic wheat stalk" and "bionic mayor"; one false positive article covered ice skater Boitano's microcomputer hardware project dubbed the Bionic Beaver. Of the relevant articles one The Globe and Mail article was concerned about a real-life Iron Man suit falling into military hands [83], one article covered therapeutic use of a bionic arm and $n=2$ covered non-therapeutic use of various forms of exoskeletons. As to the Calgary Herald $n=3$ articles covered non-therapeutic use of various forms of exoskeletons and $n=3$ articles covered therapeutic use of bionic legs and arms. One article wrote about a British eye hospital creating a new breed of 'bionic' fighters describing eye surgery that added enhanced night vision to soldiers [84]. As to The New York Times of the relevant articles $n=1$ covered therapeutic 
application of exoskeletons, $n=1$ covered non-therapeutic application of exoskeletons, $n=1$ bionic arms (although not linked to the military part of the story), $n=1$ therapeutic use of bionic arms and legs and $n=1$ an artificial heart (although none a linked to the military use of bionics or by military personal but mention military on the side like being able to deal with the heart implant procedure because one was formerly in the military). One article from 1984 mentions that a 1972 analysis by the American Defense Intelligence Agency states that "the major impetus behind the Soviet drive to harness the possible capabilities of telepathic communication, telekinetics and bionics are said to come from the Soviet military and the K.G.B" [85].

In general given the existing discourse around bionics and the military especially for non-therapeutic reasons in the literature the newspapers ignored that angle mostly and in the few cases where it is mentioned it's a sideline with no in depth analysis.

Of the articles that covered veterans and bionics, all focused on injured veterans such as the following articles in the Calgary Herald [86-88]. However, again, in depth analysis of use of the products was missing.

Of the 10 articles in the Calgary Herald that mentioned soldiers, 6 were relevant (meaning they talked about bionic products) of which three articles focused on injured soldiers and the other three articles $[84,89,90]$ covered ability enhancement of healthy soldiers indicating that this could lead to a "new breed of 'bionic' fighters" [84]. The Globe and Mail articles were also split evenly with $n=2$ focusing on injured soldiers and $n=2$ focusing on enhancing abilities of healthy soldiers. One of these $n=2$ articles from 1983 reported on the Airland Battle 2000 [91] a document by the US Army that looked at the future of warfare and which envisioned bionic soldiers [92]. As for The New York Times, $n=5$ were about injured soldiers and $n=1$ was about the enhancement of healthy soldiers. However again, the enhancement aspect was mentioned without an analysis.

\subsection{Which Products are Mentioned?}

Assistive devices are of importance to disabled people. Therefore, from a disability studies perspective it was relevant to determine which assistive devices are mentioned.

Table 2 illustrates that bionic products that replace organs are mentioned however Table 2 also reveals that the scope of mentioned body organs is limited to heart, eyes and ears although bionic replacements for nearly every body organ/part are under development including the artificial hippocampus [1-23,93].

Table 2. Bionic and related products mentioned in the newspapers.

\begin{tabular}{ccccc}
\hline Codes & $\begin{array}{c}\text { Canadian Newsstand } \\
\boldsymbol{n = 4 , 8 2 6}\end{array}$ & $\begin{array}{c}\text { Calgary Herald } \\
\boldsymbol{n = 2 7 0}\end{array}$ & $\begin{array}{c}\text { The Globe and Mail } \\
\boldsymbol{n = 3 9 2}\end{array}$ & $\begin{array}{c}\text { The New York Times } \\
\boldsymbol{n}=\mathbf{4 9 2}\end{array}$ \\
\hline Bionic organ & 1 & 0 & 0 & 0 \\
Arm & 162 & 32 & 50 & 96 \\
Brain & 24 & 29 & 39 & 71 \\
Brain computer & 6 & 0 & 0 & 1 \\
Cochlear implant & 71 & 1 & 4 & 8 \\
\hline
\end{tabular}


Table 2. Cont.

\begin{tabular}{ccccc}
\hline Codes & $\begin{array}{c}\text { Canadian Newsstand } \\
\boldsymbol{n = 4 , 8 2 6}\end{array}$ & $\begin{array}{c}\text { Calgary Herald } \\
\boldsymbol{n = 2 7 0}\end{array}$ & $\begin{array}{c}\text { The Globe and Mail } \\
\boldsymbol{n}=\mathbf{3 9 2}\end{array}$ & $\begin{array}{c}\text { The New York Times } \\
\boldsymbol{n}=\mathbf{4 9 2}\end{array}$ \\
\hline Ear & 104 & 18 & 24 & 58 \\
Exoskeleton & 21 & 3 & 1 & 7 \\
Eye & 84 & 56 & 70 & 136 \\
Foot & 3 & 38 & 50 & 114 \\
Hand & 62 & 58 & 88 & 157 \\
Heart & 726 & 39 & 59 & 104 \\
Leg & 82 & 42 & 36 & 79 \\
Liver & 45 & 2 & 8 & 8 \\
Wheelchair & 101 & 5 & 9 & 16 \\
\hline
\end{tabular}

Devices that are to be replaced by bionics such as wheelchairs and non-invasive devices such as exoskeletons that could be used to perform some of the tasks of body parts such as legs and arms are also mentioned.

\subsection{How are Bionics, Disabled People and Their Assistive Devices Portrayed?}

The language used by newspapers is an indicator of the newspaper's mindset and influences the reader. How disabled people and their assistive devices are portrayed is one focus of disability studies scholars as disability studies questions the medical portrayal of disabled people and argues for a focus on the social barriers they face. The disability rights movement coined the term ableism [73] to highlight the species-typical ability expectations the so called abled bodied people have which leads the so called abled-bodied to label the ones without these abilities as defective as unhealthy in need of a medical fix and the disablism [94] often linked to this labeling.

Table 3 shows that newspapers are heavily weighted towards a medical depiction of bionics, which is evident in the social groups mentioned (amputee, patient nurse, caregiver, therapist and physician) and the high frequency of health terms (health, disease, impairment and treatment) used.

Table 3. Medical language evident in the newspaper coverage of bionics.

\begin{tabular}{ccccc}
\hline Codes & $\begin{array}{c}\text { Canadian Newsstand } \\
\text { Complete } \boldsymbol{n}=\mathbf{4 , 8 2 6}\end{array}$ & $\begin{array}{c}\text { Calgary Herald } \\
\boldsymbol{n}=\mathbf{2 7 0}\end{array}$ & $\begin{array}{c}\text { The Globe and } \\
\text { Mail } \boldsymbol{n}=\mathbf{3 9 2}\end{array}$ & $\begin{array}{c}\text { The New York } \\
\text { Times } \boldsymbol{n}=\mathbf{4 9 2}\end{array}$ \\
\hline Amputee & 118 & 12 & 12 & 13 \\
Caregiver & 4 & 0 & 0 & 9 \\
Disease & 321 & 24 & 21 & 41 \\
Health & 510 & 31 & 34 & 57 \\
Impair* & 71 & 3 & 0 & 71 \\
Nurses & 33 & 3 & 8 & 3 \\
Patient & 323 & 27 & 33 & 60 \\
People with & & & & \\
Disabilities/disabled & $8 / 27$ & $0 / 1$ & $0 / 0$ & $1 / 5$ \\
people & & & & \\
Physicians & 46 & 4 & 8 & 9 \\
Therapist & 75 & 4 & 7 & 36 \\
Treatment & 206 & 23 & 18 & \\
\hline
\end{tabular}


Another indicator of the overall medical mindset of the reporting is that although cochlear implants [95-110] are covered in the newspapers, the term Deaf culture, a marker for whether cochlear implants should be used and whether being deaf is a defect that must be fixed, is hardly mentioned (Table 4). Deaf culture was mentioned in only one newspaper article from The Globe and Mail, one article from The New York Times and not at all in the Calgary Herald. The article from The Globe and Mail explains both sides of a debate on whether or not deaf children should use cochlear implants. Proponents believe that deaf individuals should be able to use cochlear implants as "valuable tools" to gain more opportunities and abilities [111]. Those who are opposed specifically object to parents making the decision for their children to use cochlear implants as they view implant use as "child abuse" for many reasons. The reasons being the fact that using the implant requires a surgery, trying to "fix" a child that there is nothing wrong with, and taking the child away from Deaf culture which has its "own language (sign language), values, traditions and ways of behaving" [111]. Opponents fear that children who use the implant belong neither to the hearing world or the Deaf world [111]. Within the articles retrieved from the Canadian newsstand complete, the ratio between "cochlear implants" and "Deaf culture" was 10:1.

Table 4. Frequency of use of deafness related terms.

\begin{tabular}{ccccc}
\hline Codes & $\begin{array}{c}\text { Canadian Newsstand } \\
\text { Complete } \mathbf{n = 4 , 8 2 6}\end{array}$ & $\begin{array}{c}\text { Calgary Herald } \\
\mathbf{n = 2 7 0}\end{array}$ & $\begin{array}{c}\text { The Globe and } \\
\text { Mail } \boldsymbol{n}=\mathbf{3 9 2}\end{array}$ & $\begin{array}{c}\text { The New York } \\
\text { Times } \boldsymbol{n}=\mathbf{4 9 2}\end{array}$ \\
\hline Deaf Culture & 7 & 0 & 1 & 1 \\
Cochlear implant & 71 & 1 & 4 & 8 \\
\hline
\end{tabular}

Another issue related to language is the portrayal of assistive devices that are in direct competition with bionics. Disability studies questions the negative language often used to portray assistive devices used by disabled people (e.g., confined to the wheelchair, wheelchair bound). To stay with the example of the wheelchair; 101 articles in the Canadian Newsstand Complete that mentioned bionics also mentioned wheelchairs. From a disability studies perspective, the negative portrayal of wheelchairs is problematic and is evident in discourses around artificial legs $[33,35]$. This negative coverage was also evident in the articles in the Canadian Newsstand Complete with the frequent use of the terms "wheelchair bound" [112-117], "confined to the wheelchair" [118,119] or "dependence on a wheelchair" [120,121].

Textbox 1: Negative portrayal of wheelchairs

"Gore, who played sports in high school and worked on the family farm before his fall, is eager to see prices drop and insurers decide that the expense of an exoskeleton outweighs the medical costs of keeping the disabled in wheelchairs"[112];

"to help people who use wheelchairs to stand and walk again"[122];

"Harder to quantify are intangible benefits, such as what it means for someone who has been in a wheelchair for decades to simply to be able to stand, walk around and look people in the eye again" [122];

"As soon as I was out of the wheelchair, I was teaching myself to walk again as well as swim" [115];

"That's one of the reasons I was successful at it, because it was a new me, a new normal... 
It gives me a huge sense of freedom that someone using a wheelchair will never have" [123]; "He had a prosthetic leg, but usually opted to use a wheelchair because it was easier to get around. Walking with his artificial metal leg, which has a locked knee joint, was a challenge... Blake will soon have the freedom to walk where he chooses with a C-Leg Compact, manufactured by Otto Bock" [124];

"Amanda Boxtel stands from her wheelchair and takes a few tentative steps. She beams as the bionic skeleton she is wearing helps propel her legs forward. Bionic skeletons, known as exoskeletons, are the latest technology in the race to help paraplegics achieve the impossible and walk again" [125];

"After years spent learning to live and thrive in a wheelchair, Mr. Bobblitt has a new set of goals. 'I don't really focus on walking because you don't want to get your hopes up,' he said. 'But just being able to stand up out of the chair and transfer to the bed or get something off the counter makes me wonder what else might be possible down the road" [126];

'I can't image where I'd be without it, she says. It's kept me out of a wheelchair and let me live a normal life" [127];

“'Once you get into a wheelchair, it's all part of this downward spiral,' said Burgess, a former professor of physical education" [128];

"She says that without the operation she would have been bed-ridden or at least in a wheelchair and on sedatives all the time" [128];

"getting people out of wheelchair [sic]" [129] .

The above negativity of wheelchairs was linked to not being able to stand, not being able to look people in the eye, not being able to walk, livelong cost of being in a wheelchair, wheelchair being a non-normal life, wheelchair being part of the problem juxtaposing the wheelchair with a device of liberation (C-leg or bionic exoskeleton). The framing reflects the dominant reality of the ability expectation of walking (legism [35]). The newspapers ignore an alternative narrative that questions the ability expectation of walking and the unwillingness of people to accommodate and accept non-walking alternatives such as wheelchairs and their users. The quotes reflect a narrative of perceiving the person in the wheelchair and their way of functioning as the problem versus perceiving leg-ism as the problem.

A positive portrayal of wheelchairs only occurred twice; "On February 18, Moore sat in a wheelchair for the first time... It's such an incredible joy for me to get out of bed" [130]; and "An exoskeleton might give better access to nature and areas where wheelchairs have trouble, such as on grass, gravel and sand. On the other hand, Jaimie Borisoff, a paraplegic following a spinal cord injury 20 years ago, said he probably wouldn't use it outside because he can go places much more quickly in a wheelchair" [125].

\subsection{What Issues are Mentioned?}

Another disability studies interest is to understand whether social issues are mentioned in regards to a given topic and if so, which issues are mentioned and whether they are linked to disabled people.

In general, Table 5 shows that not many social issues are mentioned in regards to bionics and of the ones mentioned many are rarely mentioned. "Cost" is the issue mentioned most. Content linked to the term "problem" could have covered various social issues. However only six out of $725(0.83 \%)$ articles 
with the term "problem" were found to present problems linked to the use of bionics. Three articles mentioned issues with the quality of devices (e.g., [131-133]) and one article from The Globe and Mail discussed tampering with bionic organs through the computers which control them, leading to untraceable murders [134]. One article from 2007 talking about Oscar Pistorius long before it became a hot media issue states: "Some little Frankenstein out there may devise a problem the [International Association of Athletics Federations] can't handle, Mr. Gramantik said" [135]. One article in the Calgary Herald thematized the utility of bionic arms, "[t]he problem, explains Carey, is the success rate of complex, technologically advanced myoelectric arms that cost between $\$ 30,000$ and $\$ 100,000$. Currently, most of the patients that get fitted with one reject it and it ends up sitting on the shelf, said Carey" [136].

Table 5. Frequency of social issues mentioned.

\begin{tabular}{ccccc}
\hline Codes & $\begin{array}{c}\text { Canadian Newsstand } \\
\text { Complete } \boldsymbol{n}=\mathbf{4 , 8 2 6}\end{array}$ & $\begin{array}{c}\text { Calgary Herald } \\
\boldsymbol{n}=\mathbf{2 7 0}\end{array}$ & $\begin{array}{c}\text { The Globe and } \\
\text { Mail } \boldsymbol{n = 3 9 2}\end{array}$ & $\begin{array}{c}\text { The New York } \\
\text { Times } \boldsymbol{n}=\mathbf{4 9 2}\end{array}$ \\
\hline Access & 165 & 13 & 14 & 21 \\
Afford* & 32 & 4 & 13 & 21 \\
Equity/equality & $30 / 22$ & $1 / 0$ & $5 / 6$ & $5 / 2$ \\
Income/cost & $77 / 715$ & $3 / 33$ & $16 / 53$ & $16 / 83$ \\
Discrimination & 11 & 1 & 2 & 2 \\
Stigma & 7 & 0 & 0 & 2 \\
Quality of life & 54 & 6 & 4 & 3 \\
Education & 175 & 12 & 18 & 27 \\
Employment & 38 & 1 & 3 & 7 \\
Problem & 504 & 50 & 77 & 133 \\
\hline
\end{tabular}

These six articles cover four different problems but the frequency of coverage is so low that it's doubtful that the reporting had a significant impact.

However most of the times the term "problem" was used to highlight problems that bionic products will solve adding to an overly positive portrayal of bionics (textbox 2).

Textbox 2: Problems seen to be solved through bionics

As to articles in the Calgary Herald:

"The promise of microchip medicine lies not only in bionic body parts, but also long-term care for chronic problems" [137]; “to answer Japan's most pressing economic and social problem: the plunging birthrate and rapid aging of the population, allowing people to work into their old age. "The suit will allow elderly people to fend for themselves much later into their retirement, and means that people do not become bed- ridden so soon in life" [138].

As to articles in The New York Times:

"In hospitals of the future "emancipated medical machines" will see problems and correct them expertly, with no need for human input. Doctors and nurses will supervise robots smart and dumb: the smart ones will perform surgery unerringly, while the dumb ones will do all the menial labor, cleaning floors, and lifting and turning patients, "freeing the warm hands of humans to better care for other humans in need" [139]; 
"Scientists and engineers have turned their tool-making and building skills to correcting the medical problems the body cannot fix. The result is a growing array of artificial body parts that are available for immediate use and many more in various stages of development around the world. From the top of the head to the bottom of the feet, it is becoming increasingly possible to use artificial parts to enhance vision and hearing, strengthen weakened bones, bolster or replace faltering organs, replace damaged joints, substitute for disabled nerves or improve appearance. Transplanting organs and other tissues from one human to another, or even from animals to humans, are other means to this end. But this avenue has been hampered by chronic shortages of donor organs, problems of compatibility and rejection, concerns about transmitting infections and other problems. Receiving artificial body parts has become so common that it no longer seems exotic. Each year, hundreds of thousands of Americans get artificial hips and knees, and tens of thousands receive heart valves, tooth implants, spine supports, eye lenses and other replacements. In addition, hundreds of thousands benefit from implantable devices that assist disabled organs or other body components but do not replace them. Examples of these include cardiac pacemakers and defibrillators to maintain regular heartbeats and rhythms, internal braces and splints to strengthen weakened or shattered bones and penile implants to treat impotence" [140];

"In the last five years, we've seen advances in many types of devices that are implanted into the body, or are external to it, that are taking over for impaired functions," said Dr. Susan Alpert, director of the Office of Device Evaluation at the Food and Drug Administration, which regulates such products" [140];

"With advances that we are seeing in material science, miniaturization and electronics, one day we may see many new devices to replace or supplement body functions that are lost” [140].

The quotes exhibit a framing of bionic devices as positive, as tools of liberations, as tools to solve a problem caused by an ability-wise non-normative body. A framing of bionics that highlights problems caused by the devices or the narrative around the devices is absent. Cost is thematized as a problem external to the device.

\subsection{The Issue of Enhancement}

Although numerous issues linked to therapeutic and non-therapeutic enhancement applications of bionics is discussed in the literature, this topic was not thematized as problematic in the newspapers if they were mentioned in the first place. The enhancement theme only shows up in regards to soldiers and the military (see above coverage of soldiers, veterans and the military) and in relation to TV shows (Table 6) where the newspaper supplied information of show times instead of reflecting on the social issues of enhancements. 
Table 6. Frequency of use of terms related to superpowers.

\begin{tabular}{ccccc}
\hline \multirow{2}{*}{ Codes } & $\begin{array}{c}\text { Canadian Newsstand } \\
\text { Complete } \boldsymbol{n = 4 , 8 2 6}\end{array}$ & $\begin{array}{c}\text { Calgary Herald } \\
\mathbf{n = 2 7 0}\end{array}$ & $\begin{array}{c}\text { The Globe and } \\
\text { Mail } \boldsymbol{n = 3 9 2}\end{array}$ & $\begin{array}{c}\text { The New York } \\
\text { Times } \boldsymbol{n}=\mathbf{4 9 2}\end{array}$ \\
\hline Bionic man & 373 & 22 & 25 & 39 \\
Bionic woman & 1,166 & 70 & 142 & 98 \\
Six million dollar man & 357 & 19 & 22 & 19 \\
\hline
\end{tabular}

The most talked about show is The Bionic Woman which appears in 33.49\% of The Globe and Mail articles, and $23.26 \%$ of the Calgary Herald articles. Interestingly one article from The Globe and Mail discussed a child who was no longer considered "the black sheep" because of his physical impairment. Instead, children like him "become the envy" of their peers, because they are like "the Six-Million-Dollar-Man" from television [141].

\section{Discussion}

According to Entman, "frames call attention to some aspects of reality while obscuring other elements, which might lead audiences to have different reactions" [79] and frames in a news text are "really the imprint of power-it registers the identity of actors or interests that competed to dominate the text" [79].

\subsection{Framing Potential Users of Bionics and Their Existing Assistive Devices}

Our study revealed an overly medical portrayal of individuals with disabilities as patients who need to be fixed (Section 3.3). Articles connect wearing of bionics to a longer and healthier life as well as enabling a better quality of life. For example, a quote from The Globe and Mail states that, "the development of bionic fingers that can be controlled and moved by patients to act like real fingers is a major step forward, and could significantly improve the quality of life of those struggling with missing digits..." [142]. One article form the Calgary Herald discussed a company in Quebec that creates new prosthetic limbs stating that they give "...amputees a better quality of life" [143]. Furthermore, the newspapers leave the reader with the idea that the more bionics mimic the "real thing", the more normal and valued it is [142]. One article from The Globe and Mail discussed a child who was no longer considered "the black sheep" because of his physical impairment. Instead, children like him "become the envy" of their peers, because they are like "the Six-Million-Dollar-Man" from television [141].

The framing of disabled people and bionics within a species-typical ability expectation reinforces a form of ability normalization that expects certain species-typical abilities [73,144]; something that many individuals with disabilities, the groups linked to them and disability studies scholars contest [145-155]. It takes the heat of the need to make the physical and social environment accessible [156,157] for people who are ability diverse.

However, the problematic coverage of disabled people does not come as a surprise and is thematized by many [158-169]. Upholding cultural diversity is according to the Canadian Radio-Television and Telecommunications Commission one of the key goals of Canada's Broadcasting Act [170] whereby "cultural diversity refers to how different groups-like ethno-cultural 
minorities, Aboriginal peoples and persons with disabilities - are represented in broadcasting" [170]. "Canadians from all backgrounds, and persons with disabilities, should also be able to recognize themselves in "mainstream" TV and radio programming" [170]. The Canadian Association of Broadcasters published in 2005 a tool how to measure The Presence, Portrayal and Participation of Persons with Disabilities in Television [171]. The Equitable Portrayal Code of the Canadian Association of Broadcasters states, "in an effort to ensure appropriate depictions of all individuals and groups, broadcasters shall refrain from airing unduly negative portrayals of persons with respect to race, national or ethnic origin, color, religion, age, gender, sexual orientation, marital status or physical or mental disability. Negative portrayal can take many different forms, including (but not limited to) stereotyping, stigmatization and victimization, derision of myths, traditions or practices, degrading material, and exploitation" [172]. However, our findings show a lack of implementations of such existing guidance.

Our study also revealed a negative portrayal of existing assistive devices used by disabled people. We posit that in order for a bionic device to be presented positively in the media, the writer does not need to use a medical lens or present a hierarchy in which bionic devices are more valued than say wheelchairs. In the same way that we do not tell people who use a car or a bicycle that they are deficient or that the bicycles is worse than the car why using a medical lens to portray the bionic wearer and why to demonize wheelchairs? An alternative narrative where a bionic device or any assistive device is sold as a tool like a car is also a possibility. There is no reason why one has to define oneself as defective in order to receive a tool.

We argue that it goes against the fundamentals of human security which includes self-identity security meaning that one can assume one is accepted independent of ones set of abilities [173]. Indeed the ability to experience self-identity security is essential in other narratives such as self-esteem of women, self-esteem of elderly people, of being bold, or of being overweight to just name a few [174-179]. Not accepting disabled people for who they are, demonizing certain assistive devices such as wheelchairs as evident in the newspapers and to pit wheelchairs against bionic legs we argue is detrimental for disabled people especially given the reality that certain assistive devices such as high tech bionic legs or exoskeletons are unavailable to the majority of disabled people due to the cost involved.

The burden of normality [180] has also been identified as an issue outside of the disability studies framework. Gilbert's for example writes about the threat of a successful treatment to a patient's identity [180] and changes in social networks of a person and other problems can arise with the 'successful' body change [181].

\subsection{Framing of Bionics}

Media are seen to play an important role in influencing both the demand and supply of medical treatments [182]. The framing of the topic of bionic was nearly exclusively positive fitting with the hyping of other health technologies [183-189].

The lack of engagement with potential problems fits with the fact reported by others that Canadian newspapers rarely report on "socio-economic influences frequently cited in the research literature (and reflected in TAHF) as being most influential in shaping population health outcomes" [190] and many other health policy related discourses identifying potential problems [191]. 
It also fits with the lack of engagement with potential problems that for example the term ethics was only mentioned in $n=57$ of the $n=4,826$ articles in the Canadian Newsstand Complete that covered bionics. As to The Globe and Mail, $n=3$ articles contained the term ethics, one from 1983 on sport doping, one from 2003 on private health care and one from 2011 on a bionic suit. The Calgary Herald had $n=4$ articles however in none was ethics mentioned in relation to bionics and The New York Times had $n=8$ articles of which two were relevant one covering the area of sport and one mentioning Itskov 2045 Initiative, 2045 being the year by when Itskov believes one can upload content of a human brain into an Avatar [192].

The overly positive reporting on bionics and the lack of thematization of potential problems linked to bionics is all the more problematic given recent developments around the "health consumer". People look increasingly for health information by themselves [191] and want to shape their own health interventions [193]. There is an increasing desire towards a "quantified self" (where people diagnose themselves) [194-197] and toward patient-driven healthcare and research models [194,198], health social networks, participatory medicine and consumer personalized medicine [199-202]. The more people look for information themselves the more they are susceptible to an overly positive coverage of a technology [203]. The more they want to shape an agenda the more they are in need of good information and the more detrimental are one-sided incomplete informations. Ford calls this educational vulnerability [204].

\subsection{The Issue of Enhancement}

The aforementioned "black sheep" quote from The Globe and Mail highlights an ever increasing truth that therapeutic interventions have the potential to give recipients beyond species-typical, body linked, abilities (therapeutic enhancement [24]). It is reported that given the choice between interventions that lead to species-typical abilities or that lead to beyond species-typical abilities that disabled people would choose beyond species-typical abilities [110]. Disabled people are seen to play a key role in mainstreaming and increasing the acceptance of body enhancements beyond the species-typical for the general public [205].

From a disability studies perspective the enhancement desire poses problems because it puts more emphasis on abilities and decreases acceptance of ability diversity [206] and because it also changes the meaning of health and related concepts, it alters the perceived need for healthcare interventions and increases the pool of people competing for healthcare dollars [24,207].

However, problems identified through a disability studies lens also impact non-disabled people; for example the ability expectation problem will impact the relationship between the enhancement-haves and enhancement have nots.

\section{Conclusions}

The Canadian Radio-television and Telecommunications Commission "recognized the influence of broadcasting on viewers in its 1986 policy statement: Broadcasting is a powerful medium to reinforce (sex-role) stereotyping and can be equally powerful to correct it" [159]. Many studies highlight the ability-role stereotyping rampant in the media [158,167-169]. Our study adds to the data in relation to 
coverage of bionics by revealing ability-role stereotyping such as legism and the negative coverage of wheelchairs.

The study revealed also an overly positive portrayal of bionics with no coverage of possible negative aspects. This one sided narrative generates certain ability expectations influencing one's self-identity and how one is perceived by others and an overly positive bias toward the utility of bionics by disabled and non-disabled people. Given the high cost of bionic solutions and that individuals with disabilities and their families struggle financially and make up an over-proportional part of the poor in high [208-211] and low income countries [209,210,212] bionics will be unavailable to the majority of disabled people. Under Article 4-General Obligations State of the United Nation Convention on the rights of persons with disabilities State Parties are asked: "To undertake or promote research and development of, and to promote the availability and use of new technologies, including information and communications technologies, mobility aids, devices and assistive technologies, suitable for persons with disabilities, giving priority to technologies at an affordable cost" [213].

From a disability studies perspective the question is whether such one sided coverage of bionics will impact people's perceptions of priorities and goals related to assistive devices? Our study design does not allow us to answer the question, however others reported on the impact of news coverage on treatment demand and product priorities (e.g., [182,185]) which suggest that there might also be an impact of how bionics are covered.

Finally, it is troubling that the bionic coverage did not engage at all with the enhancement aspects of bionics and the consequences of enhancement. From a disability studies perspective this is problematic as enhancement enabling products influence ability expectations in such a way that makes it even more difficult to be accepted with one's non-enhanced abilities, which is an area the reader should be sensitized to. As is the coverage of bionics disempowers the readers as they are not given the knowledge they need to actively be involved in contemporary discourses of bionics and is not increasing the societal well-being of disabled people.

However, the finding is not surprising. It is well known that newspapers are influenced by their environment including ownership, funding, need for circulation, advertisement revenue and the readers preference for reading like-minded news [214-235]. This might account for how a topic like bionics is covered (medical, overly positive) and how disabled people are portrayed (medical, negative). Especially the reader's preference for reading like-minded news [235-237] is very problematic from a disability studies perspective as the main societal sentiment is to look at disabled people through a medical lens and as such it makes sense that many topics such as bionics are not linked to the social reality of disabled people. As Entman stated, "once a term is widely accepted, to use another is to risk that target audiences will perceive the communicator as lacking credibility-or will even fail to understand what the communicator is talking about. Thus, the power of a frame can be as great as that of language itself [79]. Indeed, we posit that a medical and negative portrayal of disabled people is what the reader expects.

If our finding makes sense given the influence, newspapers have to take into account how disabled people are getting their alternative message out. We posit no obvious answer exists to the question so far. One can ignore newspapers but no other 'one source' provides the reader with the knowledge we think they need. We posit despite the internet and social media and despite the increase in open access academic literature no easy solution exists for people to become knowledgeable on the issues 
we covered in our study and for that matter on any given issue. Indeed the flood of information available can be very disempowering as no easy way exists for the reader to judge the quality of the information provided and to judge whether all aspect related to a given issue are mentioned. We posit that disability service organizations and disability rights organizations have to be enabled to function more as a collector and disseminator of content on emerging topics that would allow them to educate their memberships. As to newspapers it is needed to find new ways or implement existing ideas (e.g., [187,238-242]) to change reader, advertiser and owner behavior and other factors that lead newspapers to report in such a problematic fashion as reported in this study.

\section{Acknowledgments}

We thank Jesse Hendrikse for comments on an earlier version of the article.

\section{Author Contributions}

Gregor Wolbring generated and supervised the research project. Sonum Panesar did the research. Gregor Wolbring and Sonum Panesar wrote the article.

\section{Conflicts of Interest}

The authors declare no conflict of interest.

\section{References}

1. Rosen, R. Bionics Revisited. In The Machine as Metaphor and Tool; Haken, H., Karlqvist, A., Svedin, U., Eds.; Springer Berlin Heidelberg: Berlin, Germany, 1993; pp. 87-100.

2. Firszt, J.B.; Holden, L.K.; Reeder, R.M.; Skinner, M.W. Speech recognition in cochlear implant recipients: Comparison of standard HiRes and HiRes 120 sound processing. Otol. Neurotol. 2009, 30, 146-152.

3. Ossur. Bionic Knee Ossur [Online], 2009. Available online: http://bionics.ossur.com/pages/306 (accessed on 19 September 2013).

4. Donoghue, J.P. Bridging the brain to the world: A perspective on neural interface systems. Neuron 2008, 60, 511-521.

5. Miller, G. Neurotechnology. Engineering a fix for broken nervous systems. Science 2008, 322, 847, doi:10.1126/science.322.5903.847.

6. Ambient Corporation Wheelchair Demonstration. Available online: http://electric-wheelchairon.net/main/live-demo-of-mind-controlled-electric-wheelchair/ (accessed on 19 September 2013).

7. Artificial Muscle Inc. Artificial Muscle Artificial Muscle Inc. [Online], 2009. Available online: http://www.artificialmuscle.com/technology (accessed on 19 September 2013).

8. Gura, V.; Ronco, C.; Davenport, A. The wearable artificial kidney, why and how: From holy grail to reality. Semin. Dial. 2009, 22, 13-17. 
9. Bañares, R.; Catalina, M.-V.; Vaquero, J. Liver support systems: Will they ever reach prime time? Curr. Gastroenterol. Rep. 2013, 15, 1-7.

10. Qin, J.; Zhang, W.; Wu, G.; Wang, C. Bionic design of articular cartilage. J. Biomed. Eng. 2008, 25, 182-185 (In Chinese).

11. Scipione, C.N.; Schewe, R.E.; Koch, K.L.; Shaffer, A.W.; Iyengar, A.; Cook, K.E. Use of a low-resistance compliant thoracic artificial lung in the pulmonary artery to pulmonary artery configuration. J. Thorac. Cardiovasc. Surg. 2013, doi:10.1016/j.jtcvs.2013.01.020.

12. Zhou, K.; Niu, S.; Bianchi, G.; Wei, X.; Garimella, N.; Griffith, B.P.; Wu, Z.J. Biocompatibility assessment of a long-term wearable artificial pump-lung in sheep. Artif. Organs 2013, 37, 678-688.

13. Shin, D.A.; Yi, S.; Yoon, D.H.; Kim, K.N.; Shin, H.C. Artificial disc replacement combined with fusion versus two-level fusion in cervical two-level disc disease. Spine (Phila Pa 1976) 2009, 34, 1153-1159.

14. Rauschmann, M.A.; Thalgott, J.; Fogarty, M.; Nichlos, M.; Kleinszig, G.; Knap, M.; Kafchitsas, K. Insertion of the artificial disc replacement: A cadaver study comparing the conventional surgical technique and the use of a navigation system. Spine (Phila Pa 1976.) 2009, 34, 1110-1115.

15. Juvenile Diabetes Research Foundation International (JDRF) (USA). FDA Approves Computer Simulator to Model Diabetes, Test Artificial Pancreas Algorithms. Juvenile Diabetes Research Foundation International (JDRF) (USA) [Online], 2009. Available online: http://www.jdrf.org/ index.cfm?fuseaction=home.viewPage\&page_id=2FE6D0FE-110A-9BB5-F888F0860E910AF3 (accessed on 19 September 2013).

16. Zheng, R.; Li, G.; He, H.; Lin, Y. Bionic dental pulp: Its potential value following root canal therapy. Med. Hypoth. 2009, 72, 129-130.

17. NSF (National Science Foundation USA). Bionics Gives Blind Woman Partial Vision. Science Monitor [Online], 2009. Available online: http://www.livescience.com/common/media/video/ player.php?videoRef=LS_090526_Artificial-Retina (accessed on 19 September 2013).

18. Hickey, H. Bionic Eyes: Contact Lenses with Circuits, Lights a Possible Platform for Superhuman Vision. University of Washington [Online], 2009. Available online: http://uwnews.org/uweek/uweekarticle.asp?visitsource=uwkmail\&articleID=39100 (accessed on 19 September 2013).

19. Jarvis, A. The Bionic Eye: Latest in Med-Tech How a Miniature Telescope could Help Patients with Damaged Retinas, 2009. Available online: http://www.techradar.com/news/world-of-tech/ the-bionic-eye-latest-in-med-tech-617848 (accessed on 19 September 2013).

20. Hewitt, J. Wireless, solar-Powered Bionic Eyes Benefit from Sub-Retinal Placement. Available online: http://www.extremetech.com/extreme/159236-wireless-solar-powered-bionic-eyesbenefit-from-sub-retinal-placement (accessed on 19 September 2013).

21. Herr, H.M.; Grabowski, A.M. Bionic ankle-foot prosthesis normalizes walking gait for persons with leg amputation. Proc. R. Soc. B Biol. Sci. 2012, 279, 457-464.

22. Strickland, E. Good-bye, wheelchair. IEEE Spectr. 2012, 49, 30-32.

23. Wallace, G.G.; Moulton, S.E.; Wang, C. Organic Bionics. In Electroactive Polymer Actuators and Devices (EAPAD) 2010; Bar-Cohen, Y., Eds.; pp. 764202-1-764202-5. Available online: http://ro.uow.edu.au/cgi/viewcontent.cgi?article=1570\&context=scipapers $\quad($ accessed $\quad$ on 19 September 2013). 
24. Wolbring, G. HTA Initiative \#23 The Triangle of Enhancement Medicine, Disabled People, and the Concept of Health: A New Challenge for HTA, Health Research, and Health Policy; Alberta Heritage Foundation for Medical Research (AHFMR): Alberta Heritage Foundation for Medical Research (AHFMR) Webpage, 2005. Available online: http://www.ihe.ca/documents/ HTA-FR23.pdf (accessed on 19 September 2013).

25. Coenen, C.; Schuijff, M.; Smits, M.; Klaassen, P.; Hennen, L.; Rader, M.; Wolbring, G. Human Enhancement Study; (IP/A/STOA/FWC/2005-28/SC35, 41 \& 45) PE 417.483; 2009. Available online: http://www.europarl.europa.eu/stoa/publications/studies/stoa2007-13_en.pdf (accessed on 19 September 2013).

26. Miles, D. DARPA's Cutting-Edge Programs Revolutionize Prosthetics, 2006. Available online: http://www.defenselink.mil/news/newsarticle.aspx?id=14914 (accessed on 19 September 2013).

27. Popular Mechanics.com. Revolutionizing Prosthetics (RP), 2007. Available online: http://www.popularmechanics.com/science/health_medicine/4220228.html?page=4 (accessed on 19 September 2013).

28. Applied Physics Laboratory, J.H.U. Armed with Ideas-APL Leads Prosthesis Development Team, 2006. Available online: http://www.jhuapl.edu/newscenter/aplnews/2006/prostheticarm.asp (accessed on 19 September 2013).

29. Caron, S.R. Battlefield Advances. Caron's Webpage [Online], 2008. Available online: http://keepourcountryfree.tripod.com/id27.html (accessed on 19 September 2013).

30. Blagdon, J. DARPA's New Mind-Controlled Prosthetics Let Patients Feel Again. Available online: http://www.theverge.com/2013/5/31/4382366/darpa-tmr-mind-controlled-prostheticssensory-feedback (accessed on 19 September 2013).

31. DARPA Revolutionizing Prosthetics. Available online: http://www.darpa.mil/Our_Work/DSO/ Programs/Revolutionizing_Prosthetics.aspx (accessed on 19 September 2013).

32. Wolbring, G. Oscar pistorius and the future nature of olympic, paralympic and other sports. SCRIPTed-J. Law Technol. Soc. 2008, 5, 139-160.

33. Tynedal, J.; Wolbring, G. Paralympics and its athletes through the lens of the New York Times. Sports 2013, 1, 13-36.

34. Weyand, P. Performance Enhancing Legs Race toward the Track Record Book. Available online: http://medicalxpress.com/news/2013-12-legs-track.html (accessed on 19 September 2013).

35. Wolbring, G. Leg-ism Leaves some Paralympic Stars out on a Limb (2012), The Conversation. Available Online: https://theconversation.com/leg-ism-leaves-some-paralympic-stars-out-on-alimb-9008 (accessed on 19 September 2013).

36. Neurogaming Conference NeuroGaming Conference and Expo. Available online: http://www.neurogamingconf.com/ (accessed on 19 September 2013).

37. Humanity Plus formerly World Transhumanist Association. What is Transhumanism? 2005. Available online: http://humanityplus.org/ (accessed on 19 September 2013).

38. Human Enhancement: Scientific Ethical and Policy Perspective for the European Union; Church and Society Commission of the Conference of European, Churches: Strasbourg, France, 2013.

39. Caligiuri, M.J. Traditional and New Enhancing Human Cybernetic and Nanotechnological Body Modification Technologies: A Comparative Study of Roman Catholic and Transhumanist Ethical Approaches; University of Ottawa: Ottawa, Canada, 2013. 
40. Irish Council for Bioethics. Human Enhancement: Making People Better or Making Better People? 2007. Available online: http://www.bioethics.ie/uploads/docs/Humanenh.pdf (accessed on 19 September 2013).

41. Williams, A.E. Good, Better, Best: The Human Quest for Enhancement Summary Report of an Invitational Workshop Convened by the Scientific Freedom, Responsibility and Law Program American Association for the Advancement of Science 1-2 June 2006. Available online: http://www.aaas.org/spp/sfrl/projects/human_enhancement/pdfs/HESummaryReport.pdf (accessed on 19 September 2013).

42. Farah, M.; Illes, J.; Cook-Deegan, R.; Gardner, H.; Kandel, E.; King, P.; Parens, E.; Sahakian, B.; Wolpe, P.R. Neurocognitive enhancement: What can we do and what should we do? Nat. Rev. Neurosci. 2004, 5, 421-425.

43. Brodey, W.M.; Lindgren, N. Human enhancement-beyond machine age. IEEE Spectr. 1968, 5, 79-93.

44. President's Council on Bioethics. Beyond Therapy: Biotechnology and the Pursuit of Happiness, 2003. Available online: http://bioethics.georgetown.edu/pcbe/reports/beyondtherapy/ (accessed on 19 September 2013).

45. Bostrom, N.; Sandberg, A. Cognitive enhancement: Methods, ethics, regulatory challenges. Sci. Eng. Ethics 2009, 15, 311-341.

46. UK House of Commons Science and Technology Committee. Human Enhancement Technologies in Sport; The Stationery Office Limited: London, UK, 2007. Available online: http://www.publications.parliament.uk/pa/cm200607/cmselect/cmsctech/67/67.pdf (accessed on 19 September 2013).

47. Savulescu, J.; Kahane, G. The moral obligation to create children with the best chance of the best life. Bioethics 2009, 23, 274-290.

48. Harris, J. Enhancing Evolution; Princeton University Press: New York, NY, USA, 2010.

49. Sparrow, R. A not-so-new eugenics: Harris and Savulescu on human enhancement. Asian Bioeth. Rev. 2010, 2, 288-307.

50. Koch, T. Enhancing who? Enhancing what? Ethics, bioethics, and transhumanism. J. Med. Philos. 2010, 35, 685-699.

51. Wasserman, D. Ethics of human enhancement and its relevance to disability rights. eLS 2012, doi:10.1002/9780470015902.a0024135

52. Bradshaw, H.G.; ter Meulen, R. A transhumanist fault line around disability: Morphological freedom and the obligation to enhance. J. Med. Philos. 2010, 35, 670-684.

53. Gilbert, F. Nano-Bionic Devices for the Purpose of Cognitive Enhancement: Toward a Preliminary Ethical Framework. In Cognitive Enhancement; Springer: Dordrecht, The Netherlands, 2013; pp. 125-138.

54. Maturo, A. Medicalization: Current concept and future directions in a bionic society. Mens Sana Monographs 2012, 10, 122-133.

55. Maturo, A. Social justice and human enhancement in today’s Bionic Society. Salute E Società 2013, 11, 15-28.

56. Langley, A. Geek Lust: Pop Culture, Gadgets, and Other Desires of the Likeable Modern Geek; Krause Publications: Fairfield, OH, USA, 2013. 
57. Salvini, P.; Datteri, E.; Laschi, C.; Dario, P. Scientific models and ethical issues in hybrid bionic systems research. Ai Soc. 2008, 22, 431-448.

58. Gross, D. Traditional vs. Modern Neuroenhancement: Notes from a Medico-Ethical and Societal Perspective. In Implanted Minds: The Neuroethics of Intracerebral Stem Cell Transplantation and Deep Brain Stimulation; Transcript Verlag: Bielefeld, Germany, 2011; p. 291.

59. Koops, B.-J.; Leenes, R. Cheating with Implants: Implications of the Hidden Information Advantage of Bionic Ears and Eyes. In Human ICT Implants: Technical, Legal and Ethical Considerations; Gasson, M.N., Kosta, E., Bowman, D.M., Eds.; T.M.C. Asser Press: The Hague, The Netherlands, 2012; pp. 113-134.

60. Gilbert, F.; Dodds, S. Is There a Moral Obligation to Develop Brain Implants Involving Nanobionic Technologies? Ethical Issues for Clinical Trials. NanoEthics August 2013, 1-8.

61. Nuffield Council on Bioethics. Novel Neurotechnologies: Intervening in the Brain, 2013. Available online: http://www.nuffieldbioethics.org/sites/default/files/Novel_neurotechnologies_ report_PDF_web_0.pdf (accessed on 19 September 2013).

62. Bostrom, N.; Ord, T. The reversal test: Eliminating status quo bias in applied ethics. Ethics 2006, 116, 656-679.

63. Adams, J. Medicalization and the market economy: Constructing cosmetic surgery as consumable health care. Sociol. Spectr. 2013, 33, 374-389.

64. Conrad, P. The discovery of hyperkinesis: Notes on the medicalization of deviant behavior. Soc. Probl. 1975, 23, 12-21.

65. Illich, I. The medicalization of life. J. Med. Ethics 1975, 1, 73-77.

66. Conrad, P. The Medicalization of Society: On the Transformation of Human Conditions into Treatable Disorders; Springer: New York, NY, USA, 2007.

67. Suissa, A.J. Addiction to cosmetic surgery: Representations and medicalization of the body. Int. J. Mental Health Add. 2008, 6, 619-630.

68. Coveney, C.M.; Nerlich, B.; Martin, P. Modafinil in the media: Metaphors, medicalisation and the body. Soc. Sci. Med. 2009, 68, 487-495.

69. Moynihan, R.; Heath, I.; Henry, D. Selling sickness: The pharmaceutical industry and disease mongering. BMJ 2002, 324, 886-891.

70. Polonijo, A.N.; Carpiano, R.M. Representations of cosmetic surgery and emotional health in women's magazines in Canada. Womens Health Issues 2008, 18, 463-470.

71. Center on Human Policy Law and Disability Studies Syracuse University. What is Disability Studies? Available online: http://disabilitystudies.syr.edu/what/whatis.aspx (accessed on 19 September 2013).

72. Society for Disability Studies. Mision and History, 2013. Available online: http://www.disstudies.org/about/mission-and-history (accessed on 19 September 2013).

73. Wolbring, G. Expanding ableism: Taking down the ghettoization of impact of disability studies scholars. Societies 2012, 2, 75-83.

74. Entman, R.M. Symposium framing US coverage of international news: Contrasts in narratives of the KAL and Iran air incidents. J. Commun. 1991, 41, 6-27.

75. Benford, R.D. An insider's critique of the social movement framing perspective. Sociol. Inq. 1997, 67, 409-430. 
76. Scheufele, D.A. Framing as a theory of media effects. J. Commun. 1999, 49, 103-122.

77. De Vreese, C.H. News framing: Theory and typology. Inf. Des. J. Doc. Des. 2005, 13, 51-62.

78. Spiller, N. ME++: The cyborg self and the networked city. Archit. Rev. 2004, 215, 104-104.

79. Entman, R.M. Framing: Toward clarification of a fractured paradigm. J. Commun. 1993, 43, 51-58.

80. Dahinden, U. Biotechnology in Switzerland frames in a heated debate. Sci. Commun. 2002, 24, 184-197.

81. Collins, P.A.; Abelson, J.; Pyman, H.; Lavis, J.N. Are we expecting too much from print media? An analysis of newspaper coverage of the 2002 Canadian healthcare reform debate. Soc. Sci. Med. 2006, 63, 89-102.

82. Barry, C.A. Choosing Qualitative Data Analysis Software: Atlas/ti and Nudist Compared, 1998. Available online: http://www.socresonline.org.uk/socresonline/3/3/4.html (accessed on 19 September 2013).

83. Barton, A. The Iron Man Suit: Turning sci-fi into Fact. The Globe and Mail 7 November 2011, L3.

84. Peek, L. Surgery Helps Soldiers See at Night. Calgary Herald 9 April 2005, A19.

85. Broad, W.J. Pentagon is Said to Focus on ESP for Wartime Use. New York Times 10 January 1984, C1.

86. Ryan, D. Student Fights for Funds to Help Wounded Vet; Determined to Raise $\$ 150,000$ for Bionic Tool. Calgary Herald 8 December 2012, A10.

87. Retson, D. Canada's "Bionic Men" First to Receive High-Tech Arms; Neuro-Controlled Prosthetics Move as if They were Real. Calgary Herald 3 October 2008, A20.

88. US Army Funding "Bionic" Arm Project: Afghanistan, Iran Amputees Prompt Research. Calgary Herald 25 April 2006, A11.

89. Pugliese, D. Foot Soldiers can Reap Own Energy. Calgary Herald 2013.

90. Munro, M. People Power could Give Cellphones Juice; Canadian Device Harnesses Energy from Walking. Calgary Herald 8 February 2008, A9.

91. Hanson, C. Needed to Limit Casualities Bionic Troops March Ahead. The Globe and Mail 2 August 1983, N9.

92. US Army Airland Battle 2000. Available online: http://www.dtic.mil/dtic/tr/fulltext/ u2/a127471.pdf (accessed on 19 September 2013).

93. Ambient Corp. Ambient, 2011. Available online: http://www.trendhunter.com/trends/ambientaudeo (accessed on 19 September 2013).

94. Miller, P.; Parker, S.; Gillinson, S. Disablism How to Tackle the Last Prejudice; Demos: London, UK, 2004. Available online: http://www.demos.co.uk/files/disablism.pdf (accessed on 19 September 2013).

95. Padden, C.A. Deaf in America: Voices from a Culture; Harvard University Press: Boston, MA, USA, 1988.

96. Barham, J.C. Education and the deaf culture. J. Br. Assoc. Teach. Deaf 1989, 13, 110-113.

97. Brown, P.M.; Gustafson, M.S. Showing sensitivity to deaf culture. ASHA 1995, 37, 46-47.

98. Reagan, T. A sociocultural understanding of deafness-American sign language and the culture of deaf people. Int. J. Intercul. Relat. 1995, 19, 239-251.

99. Lane, H. Constructions of deafness. Disabil. Soc. 1995, 10, 171-189. 
100. Bryce, G. Cochlear implant and the deaf culture. Am. J. Otol. 1996, 17, 496-496.

101. Smith, M.E.G.; Campbell, P. Discourses on deafness: Social policy and the communicative habilitation of the deaf. Can. J. Sociol.-Cahiers Can. Sociol. 1997, 22, 437-456.

102. Tucker, B.P., The ADA and Deaf culture: Contrasting precepts, conflicting results. Ann. Am. Acad. Polit. Soc. Sci. 1997, 549, 24-36.

103. Lane, H.; Bahan, B. Ethics of cochlear implantation in young children: A review and reply from a Deaf-World perspective. Otolaryngol.-Head Neck Surg. 1998, 119, 297-313.

104. Middleton, A.; Hewison, J.; Mueller, R.F. Attitudes of deaf adults toward genetic testing for hereditary deafness. Am. J. Hum. Genet. 1998, 63, 1175-1180.

105. Clark, T.; Kammerer, B.; Smith, S.; Gulati, S. The voices of medical technology and deaf culture: Addressing the conflict for parents of deaf infants. Infant Mental Health J. 2000, 21, $365-365$.

106. Atkin, K.; Ahmad, W.I.U.; Jones, L. Young South Asian deaf people and their families: Negotiating relationships and identities. Sociol. Health Illness 2002, 24, 21-45.

107. Abberley, P. Understanding deaf culture: In search of deafhood. Disabil. Soc. 2003, 18, 971-973.

108. Ladd, P. Understanding Deaf Culture: In Search of Deafhood; Multilingual Matters: Bristol, UK, 2003.

109. Blume, S.S. The Artificial Ear: Cochlear Implants and the Culture of Deafness; Rutgers University Press: New Brunswick, NJ, USA, 2010.

110. Wolbring, G. Hearing beyond the normal enabled by therapeutic devices: The role of the recipient and the hearing profession. Neuroethics 2011, 6, 607-616.

111. Taylor, P. Canadian Studies Two Ways of Looking at Deafness Debate on Deafness The Cochlear Implant can Bring the World of Sound to Some Deaf Children. Yet Its Opponents See it as a Form of Child Abuse. The Globe and Mail 14 September 1992, A1.

112. Black, T. Startups Race for Exoskeletons; Technology Bionic Suits are Meant to Enhance Human Muscle Power. Telegraph Journal 1 April 2013, B1.

113. McGarrigle, J. Campaign for Local War Veteran Presses on. Nanaimo News Bulletin 31 January 2013, 1.

114. McGarrigle, J. Project to Help Injured War Veteran Makes Finals. Nanaimo News Bull Bulletin 21 December 2012, 1.

115. Lomas Ignites Paralympics. Marathon Athlete Lights Cauldron in London. Windsor Star 25 August 2012, E2.

116. Ayres, C. Bionic Man out of Miracles. Calgary Herald 20 September 2003, A3.

117. Horwitz, J. Some Teens may Miss Point. Standard 7 September 1999, B2.

118. Horkay, A. Paraplegics Get New Hope with Bionic Device eLegs. Guelph Mercury 14 October 2010, B10.

119. Horkay, A. Record News, s., eLegs a Step up for Paraplegics. Waterloo Region Record 14 October 2010, A8.

120. Bailey, S. Experimental Implant Helps Spinal Cord Patient Move on His Own: Research could be a Stepping Stone to Future Advances in Technology. Prince George Citizen 19 October 2001, p. 19.

121. Bailey, S. Hope for Those in Wheelchairs. Tribune 16 October 2001, B9. 
122. Price, J. Wearable Robot can Help Patients Walk again. Alaska Highway News 5 October 2012, B3.

123. Sinnema, J. Alta. rehab Centre Offers Ex-Army Amputees State-of-the-Art Lifeline. Calgary Herald 4 March 2012, B4.

124. Stern, R. Bionic Leg Offers New Lease on Life. Nanaimo News Bulletin 30 August 2011, 1.

125. Horkay, A. Bionic Legs Enable Paraplegics to Walk. Toronto Star 21 October 2010, L1.

126. Bailey, S. The Will to Walk; Paraplegic Rod Bobblitt has an Experimental Device Implanted in His Abdomen that Allows Him to Stand and Walk Brief Distances. New Brunswick Telegraph Journal 17 October 2001.

127. Baer, N. Steroids More than Athletes' Illegal Booster; Drug Family Brings Relief to Millions Series: Accolade. Ottawa Citizen 13 April 1993, A4.

128. Mullen, C. Seniors can Swing again with a Little Metal Help. Vancouver Sun 5 June 1992, C9.

129. Writer, C.M.J.S. Steely Seniors Brace for Marathon; Hip Replacements 'Dramatically Changes Their Lives,' Surgeon Says. Edmonton Journal 1 June 1992, B1.

130. Daubs, K. 'I'm Healthy, I'm Strong, I'm Alive'. Spectator 10 March 2011, GO6.

131. Tratt, K-M.; You, T. Prosthetics: Advances Bring Steady Improvement in Comfort, Form and Function. Calgary Herald 4 May 1999, W19.

132. McIlroy, A. Bionics Researchers Building a Better Hand. The Globe and Mail 22 April 2011, A17.

133. McIlroy, A. Electric Conversations. The Globe and Mail 24 May 2003, F7.

134. Reynolds, N. The Perfect Heart-Stopping Murder. The Globe and Mail 10 April 2012, A14.

135. Christie, J. Door to Beijing Games Likely Closed for Blade Runner. The Globe and Mail 21 Secember 2007, A3.

136. Professional Engineers Help Make Medical Breakthroughs. Calgary Herald 28 February 2013, F4.

137. Smith, A.D. Microchip Medicine: 'The Dawn of Something Huge'. Calgary Herald 10 June 2007, D3.

138. Lewis, L. Bionic Suit Doubles Strength of Wearer. Calgary Herald 2 July 2005, A15.

139. Abigail Zuger, M.D. The High and Low Tech of Health Care Innovation. New York Times 30 December 2008, D5.

140. Leary, W.E. The Whole Body Catalogue. New York Times 8 July 1997, 1.

141. Grant, D. Bionic Kid. The Globe and Mail 22 October 1979, p. 13.

142. Weeks, C. Bionic Digits can Mimic Moves of Lost Fingers. The Globe and Mail 9 December 2009, L4.

143. Bouchard to Try out Bionic Leg. Calgary Herald 22 April 2004, A12.

144. Susman, J. Disability, stigma and deviance. Soc. Sci. Med. 1994, 38, 15-22.

145. Imrie, R. Ableist geographies, disablist spaces: Towards a reconstruction of Golledge's 'Geography and the disabled'. Trans. Inst. Br. Geogr. 1996, 21, 397-403.

146. Ayim, M. Crimes against the Deaf: The politics of Ableism. Can. J. Educ. 1997, 22, 330-335.

147. Livingston, K. When architecture disables: Teaching undergraduates to perceive ableism in the built environment. Teach. Sociol. 2000, 28, 182-191.

148. Carlson, L. Cognitive ableism and disability studies: Feminist reflections on the history of mental retardation. Hypatia 2001, 16, 124-146. 
149. Hehir, T. Eliminating ableism in education. Harv. Educ. Rev. 2002, 72, 1-32.

150. McLean, M. Professionalising beneficence: How being a teacher can fortify ableism. J. Intell. Disabil. Res. 2004, 48, 501-501.

151. McLean, M.A. Learning and Teaching about Disability: The Possibility of Disestablishing Ableism. PhD Thesis, Faculty of Education, Deakin University, Melbourne, Australia, 2005.

152. Mackenzie, R.; Cox, S. Transableism, disability and paternalism in public health ethics: Taxonomies, identity disorders and persistent unexplained physical symptoms. Int. J. Law Context 2006, 2, 363-375.

153. Overall, C. Old age and ageism, impairment and ableism: Exploring the conceptual and material connections. NWSA J. 2006, 18, 126-137.

154. Overboe, J. Vitalism: Subjectivity exceeding racism, sexism, and (psychiatric) ableism. Wagadu J. Transnatl. Women's Gender Stud. 2007, 4, 23-34.

155. Campbell Kumari, F. Contours of Ableism The Production of Disability and Abledness; Palgrave Macmillan: New York, NY, USA, 2009.

156. Rich, R.F.; Erb, C.T.; Rich, R.A. Critical legal and policy issues for people with disabilities. DePaul J. Health Care L. 2002, 6, 1.

157. Quinlan, M.M.; Bates, B.R. Bionic woman (2007): Gender, disability and cyborgs. J. Res. Spec. Educ. Needs 2009, 9, 48-58.

158. Barnes, C. Disabling Imagery and the Media, an Exploration of the Principles for Media Representations of Disabled People; British Council of Organisations of Disabled People and Ryburn Publishing: Krumlin, Halifax, UK, 1992. Available online: http//:www.leeds.ac.uk/ disability-studies/.../disabling\%20imagery.pdf (accessed on 19 September 2013).

159. Dahl, M. The role of the media in promoting images of disability-disability as metaphor: The evil crip. Can. J. Commun. 1993, 18. Available online: http://cjc-online.ca/index.php/journal/ article/view/718/624 (accessed on 19 September 2013).

160. Clogston, J.S. Disability Coverage in American Newspapers. In The Disabled, the Media and the Information Age; Nelson, L.J., Ed.; Greenwood Press: Westport, CT, USA, 1994; pp. 45-57.

161. Nelson, J. The Invisible Cultural Group: Images of Disability. In Images that Injure: Pictorial Stereotypes in the Media; Greenwood Publisher: Santa Barbara, CA, USA, 2003; pp. 175-196.

162. Pointon, A. Framed Interrogating Disability in the Media; British Film Institute: London, UK, 1997.

163. Auslander, G.K.; Gold, N. Disability terminology in the media: A comparison of newspaper reports in Canada and Israel. Soc. Sci. Med. 1999, 48, 1395-1405.

164. Goggin, G.; Newell, C. Crippling paralympics? Media, disability and olympism. Media Int. Austr. Inc. Cult. Policy 2000, 97, 71-83.

165. Goggin, G.; Newell, C. Digital Disability: The Social Construction of Disability in New Media; Rowman \& Littlefield Pub Inc.: Lanham, MD, USA, 2003.

166. Riley, C.A. Disability and the Media: Prescriptions for Change; University Press of New England: Lebanon, PA, USA, 2005.

167. Haller, B.; Dorries, B.; Rahn, J. Media labeling vs. the US disability community identity: A study of shifting cultural language. Disabil. Soc. 2006, 21, 61-75. 
168. Haller, B.; Rioux, M.; Dinca-Panaitescu, M.; Laing, A.; Vostermans, J.; Hearn, P. The place of news media analysis within Canadian disability studies. Can. J. Disabil. Stud. 2012, 1, 43-74.

169. Haller, B.A. Don't Use the Term 'Wheelchair-Bound.' Ever. Media dis\&dat [Online], 2008. Available online: http://media-dis-n-dat.blogspot.com/2008/02/dont-use-term-wheelchair-boundever.html (accessed on 19 September 2013).

170. Canadian Radio-television and Telecommunications Commission. Cultural Diversity on Television and Radio. Available online: http://www.crtc.gc.ca/eng/info_sht/b308.htm (accessed on 19 September 2013).

171. Canadian Association of Broadcasters. The Presence, Portrayal and Participation of Persons with Disabilities in Television Programming. Available online: http://www.cab-acr.ca/english/ research/05/sub_sep1605.htm\#measuring (accessed on 19 September 2013).

172. Canadian Association of Broadcasters, Broadcasting Public Notice CRTC 2008-23. Available online: http://www.crtc.gc.ca/eng/archive/2008/pb2008-23.htm (accessed on 19 September 2013).

173. Wolbring, G. Ableism and Favoritism for Abilities Governance, Ethics and Studies: New Tools for Nanoscale and Nanoscale Enabled Science and Technology Governance. In The Yearbook of Nanotechnology in Society, Volume II: The Challenges of Equity and Equality; Cozzens, S., Wetmore, M.J., Eds.; Springer: New York, NY, USA, 2010.

174. Cruikshank, B. Revolutions within-self-government and self-esteem. Econ. Soc. 1993, 22, 327-344.

175. Atalay, A.A.; Gencoz, T. Critical factors of social physique anxiety: Exercising and body image satisfaction. Behav. Change 2008, 25, 178-188.

176. Bosson, J.K.; Pinel, E.C.; Thompson, J.K. The affective consequences of minimizing women's body image concerns. Psychol. Women Quart. 2008, 32, 257-266.

177. Donaghue, N.; Smith, N. Not half bad: Self and others' judgements of body size and attractiveness across the life span. Sex Roles 2008, 58, 875-882.

178. Tucker, P. Bald is beautiful? The psychosocial impact of alopecia areata. J. Health Psychol. 2009, 14, 142-151.

179. Weisbuch, M.; Sinclair, S.A.; Skorinko, J.L.; Eccleston, C.P. Self-esteem depends on the beholder: Effects of a subtle social value cue. J. Exp. Soc. Psychol. 2009, 45, 143-148.

180. Gilbert, F. The burden of normality: From 'chronically ill' to 'symptom free'. New ethical challenges for deep brain stimulation postoperative treatment. J. Med. Ethics 2012, 38, 408-412.

181. Wolbring, G. Obsolescence and body technologies Obsolescencia y tecnologías del cuerpo. Dilemata Int. J. Appl. Ethics 2010, 2, 67-83.

182. Benelli, E. The role of the media in steering public opinion on healthcare issues. Health Policy 2003, 63, 179-186.

183. Rivnay, J.; Owens, R.M.; Malliaras, G.G. The rise of organic bioelectronics. Chem. Mater. 2013, 26, 679-685.

184. Guyer, R.L.; Moreno, J.D. Slouching toward policy: Lazy bioethics and the perils of science fiction. Am. J. Bioethics 2004, 4, W14-W17.

185. Zuckerman, D. Hype in health reporting: "Checkbook Science" buys distortion of medical news. Int. J. Health Serv. 2003, 33, 383-389. 
186. Moynihan, R.; Bero, L.; Ross-Degnan, D.; Henry, D.; Lee, K.; Watkins, J.; Mah, C.; Soumerai, S.B. Coverage by the news media of the benefits and risks of medications. N. Engl. J. Med. 2000, 342, 1645-1650.

187. Gilbert, F.; Ovadia, D. Deep brain stimulation in the media: Over-optimistic portrayals call for a new strategy involving journalists and scientists in ethical debates. Front. Integr. Neurosci. 2011, $5,1-6$.

188. Partridge, B.J.; Bell, S.K.; Lucke, J. C.; Yeates, S.; Hall, W.D. Smart drugs "as common as coffee": Media hype about neuroenhancement. PLoS One 2011, 6, doi:10.1371/journal.pone.0028416.

189. Schwitzer, G.; Mudur, G.; Henry, D.; Wilson, A.; Goozner, M.; Simbra, M.; Sweet, M.; Baverstock, K.A. What are the roles and responsibilities of the media in disseminating health information? PLoS Med. 2005, 2, doi:10.1371/journal.pmed.0020215.

190. Hayes, M.V.; Ian, R.; Gasher, M.; Gutstein, D.; Dunn, J.R.; Hackett, R.A. Telling stories: News media, health literacy and public policy in Canada. Soc. Sci. Med. 2007, 64, 1842-1852.

191. Wolbring, G.; Leopatra, V.; Yumakulov, S. Information flow and health policy literacy: The role of the media. Information 2012, 3, 391-402.

192. Segal, D. This Man is not a Cyborg. Yet. New York Times 2 June 2013, BU1.

193. Coughlin, J.F.; Pope, J.E.; Leedle, B.R. Old age, new technology, and future innovations in disease management and home health care. Home Health Care Manag. Pract. 2006, 18, 196-207.

194. Swan, M. Emerging patient-driven health care models: An examination of health social networks, consumer personalized medicine and quantified self-tracking. Int. J. Environ. Res. Public Health 2009, 6, 492-525.

195. Dvorsky, G. The Quantified Self: 6 Tools to Help You Get Started. Institute of Ethics and Emerging Techologies [Online], 2010. Available online: http://ieet.org/index.php/IEET/more/ dvorsky20101106 (accessed on 19 September 2013).

196. Wolf, G. The Quantified Self. TED [Online], 2010. Available online: http://www.ted.com/ talks/gary_wolf_the_quantified_self.html (accessed on 19 September 2013).

197. Blaze Carlson, K. The Quantified Self. National Post 2 October 2010, A1.

198. Frydman, G.J. Patient-driven research: Rich opportunities and real risks. J. Particip. Med. 2009. Available online: http://www.medscape.com/viewarticle/713872 (accessed on 19 September 2013).

199. Bloss, C.S.; Ornowski, L.; Silver, E.; Cargill, M.; Vanier, V.; Schork, N.J.; Topol, E.J. Consumer perceptions of direct-to-consumer personalized genomic risk assessments. Genet. Med. 2010, 12, $556-566$.

200. Guttmacher, A.E.; McGuire, A.L.; Ponder, B.; Stef nsson, K. Personalized genomic information: Preparing for the future of genetic medicine. Nat. Rev. Genet. 2010, 11, 161-165.

201. Kato, K.; Kano, K.; Shirai, T. Science communication: Significance for genome-based personalized medicineûa view from the Asia-Pacific. Curr. Pharm. 2010, 8, 93-96.

202. Keller, M.A.; Gordon, E.S.; Stack, C.B.; Gharani, N.; Sill, C.J.; Schmidlen, T.J.; Joseph, M.; Pallies, J.; Gerry, N.P.; Christman, M.F. Coriell personalized medicine collaborative: A prospective study of the utility of personalized medicine. Person. Med. 2010, 7, 301-317.

203. Racine, E.; Waldman, S.; Palmour, N.; Risse, D.; Illes, J. "Currents of hope": Neurostimulation techniques in US and UK Print Media. Cambr. Quart. Healthcare Ethics 2007, 16, 312-316. 
204. Ford, P.J. Vulnerable brains: Research ethics and neurosurgical patients. J. Law Med. Ethics 2009, 37, 73-82.

205. Hughes, J. Citizen Cyborg. Why Democratic Societies Must Respond to the Redesigned Human of the Future; Basic Books: Jackson, MS, USA, 2004.

206. Wolbring, G. Is there an end to out-able? Is there an end to the rat race for abilities? J. Media Cult. 2008, 11, 3.

207. Wolbring, G. Nanotechnology and the Transhumanization of Health, Medicine, and Rehabilitation; Lee Kleinmann, D., Delborne, J., Cloud-Hansen, K., Handelsman, J., Eds.; Mar Ann Liebert: New Rochelle, NY, USA, 2010; pp. 290-303.

208. Beresford, P. Poverty and disabled people: Challenging dominant debates and policies. Disabil. Soc. 1996, 11, 553-568.

209. Yeo, R.; Moore, K. Including disabled people in poverty reduction work: Nothing about us, without us. World Dev. 2003, 31, 571-590.

210. Rosano, A.; Mancini, F.; Solipaca, A. Poverty in people with disabilities: Indicators from the capability approach. Soc. Indic. Res. 2009, 94, 75-82.

211. Huang, J.; Guo, B.; Kim, Y. Food insecurity and disability: Do economic resources matter? Soc. Sci. Res. 2010, 39, 111-124.

212. Kassah, A.K. Begging as work: A study of people with mobility difficulties in Accra, Ghana. Disabil. Soc. 2008, 23, 163-170.

213. Wolbring, G. Bionics, 'therapeutic' enhancement, the UN Convention on the rights off persons with disabilities and the way ahead. J. Int. Biotechnol. Law 2009, 6, 193-206.

214. Reese, S.D. Understanding the global journalist: A hierarchy-of-influences approach. J. Stud. 2001, 2, 173-187.

215. Price, C.J. Interfering owners or meddling advertisers: How network television news correspondents feel about ownership and advertiser influence on news stories. J. Media Econ. 2003, 16, 175-188.

216. Winseck, D. Netscapes of power: Convergence, consolidation and power in the Canadian mediascape. Media Cult. Soc. 2002, 24, 795-819.

217. Gilens, M.; Hertzman, C. Corporate ownership and news bias: Newspaper coverage of the 1996 Telecommunications Act. J. Polit. 2000, 62, 369-386.

218. Anderson, A. Media, politics and climate change: Towards a new research agenda. Sociol. Compass 2009, 3, 166-182.

219. Schudson, M. The news media as political institutions. Annu. Rev. Polit. Sci. 2002, 5, 249-269.

220. Baer, W.S.; Geller, H.; Grundfest, J.A.; Possner, K.B. Concentration of Mass Media Ownership: Assessing the State of Current Knowledge; Rand Corporation: Santa Monica, CA, USA, 1974.

221. Allport, G.W.; Faden, J.M. The Psychology of newspapers: Five tentative laws. Publ. Opin. $Q$. 1940, 4, 687-703.

222. Tilley, E.; Hollings, J. In Still Stuck in “A Love-Hate Relationship": Understanding Journalists' Enduring and Impassioned Duality towards Public Relations. In Proceedings of the ANZCA 2008 Conference, Wellington, New Zealand, 9-11 July 2008. 
223. Shoemaker, P.J.; Vos, T.P.; Reese, S.D. Journalists as Gatekeepers. In Handbook of Journalism Studies; Wahl-Jorgensen, K., Hanitzsch, T., Eds.; Routledge: New York, NY, USA, 2008; pp. 73-87.

224. McCauley, M.; Blake, K.; Meissner, H.; Viswanath, K. The social group influences of US health journalists and their impact on the newsmaking process. Health Educ. Res. 2013, 28, 339-351.

225. Sill, K.L.; Metzgar, E.T.; Rouse, S.M. Media coverage of the US supreme court: How do journalists assess the importance of court decisions? Polit. Commun. 2013, 30, 58-80.

226. Weaver, D.; Elliott, S.N. Who sets the agenda for the media? A study of local agenda-building. J. Q. 1985, 62, 87-94.

227. Carragee, K.M.; Roefs, W. The neglect of power in recent framing research. J. Commun. 2004, 54, 214-233.

228. Bulkow, K.; Urban, J.; Schweiger, W. The duality of agenda-setting: The role of information processing. Int. J. Public Opin. Res. 2013, 25, 43-63.

229. Illia, L.; Lurati, F.; Casalaz, R. Situational theory of publics: Exploring a cultural ethnocentric bias. Int. J. Public Opin. Res. 2013, 25, 93-122.

230. Roberts, M.; McCombs, M. Agenda setting and political advertising: Origins of the news agenda. Polit. Commun. 1994, 11, 249-262.

231. Abbring, J.H.; van Ours, J.C. Selling news and advertising space: The economics of Dutch newspapers. Economist 1994, 142, 151-170.

232. Reddaway, W.B. The economics of newspapers. Econ. J. 1963, 73, 201-218.

233. George, L. What's fit to print: The effect of ownership concentration on product variety in daily newspaper markets. Inf. Econ. Policy 2007, 19, 285-303.

234. White, J.M. Source Choice in Agricultural News Coverage: Impacts of Reporter Specialization and Newspaper Location, Ownership, and Circulation. Available online: http://repository.tamu.edu/ bitstream/handle/1969.1/ETD-TAMU-1033/WHITE-DISSERTATION.pdf?sequence=1 (accessed on 19 September 2013).

235. Gentzkow, M.; Shapiro, J.M. What drives media slant? Evidence from US daily newspapers. Econometrica 2010, 78, 35-71.

236. Arceneaux, K. Niche News: The Politics of News Choice. In Political Communication; Jomini Stroud, N., Ed.; Oxford University Press: England, UK, 2011; Volume 28, pp. 466-468.

237. Stroud, N.J.; Muddiman, A. Selective exposure, tolerance, and satirical news. Int. J. Public Opin. Res. 2013, 25, 271-290.

238. Pellechia, M.G. Trends in science coverage: A content analysis of three US newspapers. Public Underst. Sci. 1997, 6, 49-68.

239. Bubela, T.; Nisbet, M.C.; Borchelt, R.; Brunger, F.; Critchley, C.; Einsiedel, E.; Geller, G.; Gupta, A.; Hampel, J.; Hyde-Lay, R. Science communication reconsidered. Nat. Biotechnol. 2009, 27, 514-518.

240. Ransohoff, D.F.; Ransohoff, R.M. Sensationalism in the media: When scientists and journalists may be complicit collaborators. Effect. Clin. Pract: ECP 2001, 4, 185-188.

241. Murcott, T.H.; Williams, A. The challenges for science journalism in the UK. Progr. Phys. Geogr. 2013, 37, 152-160. 
242. Brossard, D. New media landscapes and the science information consumer. Proc. Natl. Acad. Sci. USA 2013, 110, 14096-14101.

(C) 2014 by the authors; licensee MDPI, Basel, Switzerland. This article is an open access article distributed under the terms and conditions of the Creative Commons Attribution license (http://creativecommons.org/licenses/by/3.0/). 